\title{
MULTIDIMENSIONAL CHARACTERIZATION OF THE REGIONAL URBAN MODEL AND THE URBAN SPRAWL IN VALENCIA
}

\author{
ERIC GIELEN, JOSÉ LUIS MIRALLES I GARCIA \& GABRIEL RIUTORT MAYOL \\ Department of Urbanism, Universitat Politècnica de València, Spain.
}

\begin{abstract}
The big urban development produced in Spain about last 30 years has produced a paradigm shift in the regional urban model. The traditionally compact city has become a scattered city. This phenomenon is usual in the American model but is relatively new in Spain and in the European context.

Many of the contemporary cities present an urban sprawl model. In this situation, the city is not only constituted by its historical nucleus and its extension, but also includes discontinuous urban land. Therefore, new analysis tools are needed.

This paper shows a part of $\mathrm{PhD}$ research and studies the characterization of the pattern of urban occupation from a morphological perspective. The application of multivariate statistical techniques allows to reduce an initial set of 12 variables in five independent dimensions: density, fragmentation, distance, complexity and extension.

It is shown that the urban sprawl is a multidimensional phenomenon. The research conclude that urban sprawl is an urban model of occupation of the territory, characterized by low density settlements spread over large areas, fragmented in several urban units, distant between them and defining a complex structure.

The research has been carried out in the Valencian Community at the municipal level. As a result, the five dimensions of the urban model have been calculated to all municipalities. This has allowed to identify processes of urban dispersion in the coastal areas and the metropolitan areas of the most important cities.
\end{abstract}

Keywords: Urban sprawl dimensions, Valencian community, multidimensional regional analysis, multivariate statistical techniques

\section{INTRODUCTION}

The traditional Mediterranean urban model is characterized by its compactness and social diversity. This model was changing to a new urban model as a say Moreira [1]. Although with singularities according to the place [2-4], the European urban model is now more dispersed [5, 6]. Until recently, the urban sprawl was a phenomenon typical of America but currently it is has produced all over the world [7]. In Spain, the urban sprawl phenomenon was occurred mainly over three economic expansive periods associated with three real estate bubbles and produces a non-sustainable urban development [8, 9]. Since 1959 to 1972, the first period occurred when Spain opened borders to foreign investment and the touristic development of coastal zones started. The second period, since 1985 to 1990, produced a very extensive urban development on Mediterranean coast, after the entry of Spain into the European Economic Community. Finally, the third period, since 1997 to 2006, was produced by financial leverage of families and business especially in mortgage credits. It is necessary to now the phenomenon if we want analyse the relationship between urban sprawl and sustainability.

For a long time, the urban sprawl phenomenon has studied, especially in USA. Despite that, still now the phenomenon is not well known. It exist a lot of numerical methodologies that try to measure it. However, it is not an easy task. On the one hand, the phenomenon is complex and multidimensional. On the other hand, the measurement of phenomenon depends 
of geographical limits, work scale and its definition. That is, it exist many definitions for the urban sprawl phenomenon and it measurement depend of the definition. Often different measurements of phenomenon are not comparable between them.

In this article, the authors consider the most morphological characteristics of urban sprawl and the definition could be the following:

The scattered city (urban sprawl) is an urban model of land cover characterized by lowdensity settlements extended on big surfaces, fragmented in some urban communities, which are located in places far between them and all these elements make up a complex structure.

This article shows a partial result of the research works carried out in the doctoral thesis developed by Eric Gielen [10].

\section{MATERIAL AND METHOD}

It is possible to analyse geographical phenomenon by the use of geographical database. Particularly, for Valencian Community, it exist SIOSE database, with geographical data of 2011, in Instituto Cartográfico Valenciano (ICV), the Instituto Nacional de Estadística (INE) where is the national census of population and houses for 2011 and the Instituto Geográfico Nacional (IGN) get the municipal borders. These databases are accessible on-line and allows realising geographical analysis at municipal level.

SIOSE is a geographical database that includes land uses distribution, especially urban uses. Each polygon (or geographical data unit) can be one or more data cover: simple when the polygon has the same data to all of it and association when the polygon has a combination of some simple cover into it. This research was focused in cover named Urban Mixt. This cover includes the association of following uses: urban centre, example (expansion district) and discontinuous. Each of these three covers includes a mixt of different urban elements: buildings, streets, gardens, swimming pools, others. In addition, each element includes different kinds. For example, we can find different kind of buildings: isolated buildings, buildings between dividing wall, isolated single-family house and attached single-family house.

All this geographical information allows a very detailed analysis of urban uses distribution. Below we present the methodology of analysis.

On a first phase it was selected a list of indicators that can explain the urban sprawl from a large list of the proposal of different authors. In fact, first, it was obtained all urban sprawl indicators proposed from a large list of authors. This first list of indicators was tested by a Geographic Information System (GIS), specifically ArcGIS of ESRI. The test consisted in applying each indicator in the sample formed by all the municipalities of the Valencian Community. According to the result, was selected the indicators that produced urban sprawl maps similar to real situation.

These indicators selected was considerate as variables that can explain urban sprawl phenomenon. On a second phase, it has been done a correlation analysis and an analysis of principal dimensions. These analyses was realized by multivariate factor techniques: multivariate factor analysis and principal components analysis (PCA). The final objective is identifying the latent variables that explain the phenomenon.

As a result, it was possible that some dimensions characterize the municipal urban model of land uses. In addition, as a consequence, the level of urban sprawl of each municipality of Valencian Community.

\section{VARIABLES}

After the first phase, it was selected a list of 12 variables that probably can explain the urban sprawl phenomenon at municipal level. Table 1 shows these variables. 
Table 1: List of indicators selected to factor analysis.

\section{Indicator name}

Formula

Net density $\left(\mathrm{m}^{2} / \mathrm{m}^{2}\right)[11]$

$$
\text { NetDen }=\frac{\sum_{i=1}^{n}\left(\frac{\sum_{a=1}^{p}\left(E F_{i}^{a} * K_{a}\right)}{S_{i}}\right)}{n}
$$

$E F_{i}^{a}$ : built-up roof surface kind a urban zone $i$

$K_{a}$ : quantity of floor for built-up kind $a$

$S_{i}$ : surface of urban zone $i$

$n$ : number of urban zones

Discontinuous surface

(\%)

$$
\operatorname{Disc}=\frac{D I S}{S}
$$

$D I S$ : discontinuous urban zone surface

$S$ : municipality surface

Urban zones

concentration $(\%)$

$$
C \text { Cont }=\frac{C}{C+D I S}
$$

$C$ : Surface of continuous urban zones

$D I S$ : Surface of discontinuous urban zones

Houses concentration (\%)

$$
C E d i f=\frac{E D}{E D+V I V}
$$

$E D$ : built-up roof surface of multifamily residential buildings

$V I V$ : built-up roof surface of single family home buildings

Public spaces density $\left(\mathrm{m}^{2} / \mathrm{m}^{2}\right)$

$$
\text { FSpace }=\frac{Z V_{i}+V_{i}}{V i v_{i}}
$$

$Z V_{i}:$ surface of green zones

$V_{i}$ : Surface of public streets

$\mathrm{Viv}_{\mathrm{i}}$ : number of houses (Population and Houses Census, 2011)

Form index

(a-dimensional)

$$
\text { Shape }=\frac{\sum_{i=1}^{n}\left(\frac{p_{i}}{\sqrt{\pi S_{i}}} * S_{i}\right)}{\sum_{i=1}^{n}\left(S_{i}\right)}
$$

$p_{i}$ : perimeter of urban zone $\mathrm{i}$

$S_{i}$ : Surface of urban zone i

$n$ : number of urban zones

Fractal dimension (a-dimensional)

$$
\text { Fractal }=\frac{\sum_{i=1}^{n}\left[\frac{2 * \ln \left(0,25 * p_{i}\right)}{\ln \left(S_{i}\right)} * S_{i}\right]}{\sum_{i=1}^{n}\left(S_{i}\right)}
$$


Table 1: (Continued)

\section{Indicator name}

Fragmentation degree (a-dimensional)

Concentration index (a-dimensional) [12]

\section{Formula}

$p_{i}$ : perimeter of urban zone $i$

$S_{i}$ : Surface of urban zone $i$

$n$ : number of urban zones

$$
\text { Frag }=-1 * \sum_{i=1}^{n}\left\{\frac{S_{i}}{\sum_{i=1}^{n} S_{i}} *\left[\ln \left(\frac{S_{i}}{\sum_{i=1}^{n} S_{i}}\right)\right]\right\}
$$

$S_{i}$ : surface of urban zone $i$

$n$ : number of urban zones

$$
\text { Gini }=\frac{\sum_{i=0}^{n}\left(1-Q_{i}\right)}{n}
$$

$Q_{i}$ : accumulated percentage of urban zone $i$ with respect to the total urban area

$n$ : number of urban zones

Distance to the city centre (meters)

$$
\text { Dist }=\frac{\sum_{i=0}^{n}\left(d_{i}^{*} \frac{E F_{i}}{\sum_{i=1}^{n}\left(E F_{i}\right)}\right)}{n}
$$

$E F_{i}$ built-up roof of kind a into urban zone $i$

$d_{i}$ : distance from urban zone $i$ to the city centre $n$ : number of urban zones

Standard deviation of distance to the city centre (meters)

$$
s d \text { Dist }=\sqrt{\frac{\sum_{i=0}^{n}\left(d_{i}-\frac{\sum_{i=0}^{n}\left(d_{i} * \frac{E F_{i}}{\sum_{i=1}^{n}\left(E F_{i}\right)}\right)}{n}\right)^{2}}{n-1}}
$$

$d_{i}$ : distance from urban zone $i$ to the city centre

$E F_{i}$ : built-up roof kind a into urban zone $i$

$n$ : number of urban zones

Variation coefficient of distance to the city centre (meters)

$$
c v \text { Dist }=\frac{s d \text { Dist }}{\sum_{i=0}^{n}\left(d_{i} * \frac{E F_{i}}{\sum_{i=1}^{n}\left(E F_{i}\right)}\right)}
$$

$s d D i s t$ : standard deviation of distances from urban zones $i$ to the city centre

$E F_{i}$ : built-up roof kind a into urban zone $i$ $n$ : number of urban zones 


\section{IDENTIFYING DIMENSIONS OF URBAN SPRAWL}

The urban sprawl phenomenon is complex. In fact the phenomenon can be produced by different causes: expansion of low density residential zones, expansion of urban areas isolated between them, expansion of non-concentrate urban areas... In consequence, the different indicators can represent different kind of phenomenon. That is, it can be some different dimensions associated to the list of indicators. In this case, it is possible use statistic techniques to find possible latent variables. In this research has been applied two kinds of multivariate statistics techniques: multivariate factor analysis (FA) and independent components analysis (ICA). They are two different techniques with similar objectives. These two techniques have been applied to compare results between them. These techniques allow finding latent variables or factors. Each one of the factors are integrated by a set of input indicators, which largely vary in the same direction and therefore explain similar information.

The ICA method is better suited for the goals sought in this research. On the one hand, it uses a criterion of statistical independence to identify the factors and, on the other hand, it is especially designed for normal and non-normal (asymmetric) variables that is the case of some of our variables. However, the ICA algorithm can produce not-unique solutions [13], in function of quality, quantity and good variable distributions. This is the reason for what the results of the ICA method must be contrasted by other techniques such as the multivariate factor analysis (FA).

The ICA method allows for identifying the latent variables or factors that share minimal information between them (Mutual information-based method) [14]. The ICA method has the objective of decomposing the original set of variables as a lineal combination of new components statically independents each other, according to eqn (1):

$$
X_{\left(I^{* J}\right)}=S_{\left(I^{*} K\right)} \cdot A_{\left(K^{*} J\right)}
$$

Where:

- $X$ matrix $(I * J)$ contains each one of original variables $j$ for each one of municipalities $i$

- $S$ matrix $(I * K)$ contains each one of new independent components $k$

- A matrix $(K * J)$ contains the contributions of each variable to lineal combination.

So, matrix $S$ contains the new lantent factors, and the matrix $A$ the contributions to the linear combination. The contribution values (see Table 2) indicate the importance of each original variable in the linear combination or vice versa. Table shows the new components Dim 1-5 defined as a combination of original variables according to coefficients. The variables with major contribution for each new component are marked in the same table. The analysis was done for 12 original variables and the 542 municipalities of Valencian Community.

In addition, the multivariate factor analysis (FA) is used to contrast the results obtained for the ICA analysis. The FA method uses the same equation to solve the lineal combination between the original set of variables $X$ and new latent variables $S$. This is achieved by formulating a linear model according to the linear correlation structure of the data. Calculations are made using the maximum likelihood method [15] and the Robustfa of the $R$ statistical software has been used for this purpose. Table 3 shows variable contributions of the linear combination obtained in the FA method.

Both statistical methods applied, ICA and FA, produces similar results. The main difference between both results is focused in Disc variable. By FA method, the variable Disc contributes to 1, 2 and 5 dimensions. In contrast, by ICA method, the variable Disc only contributes to dimension 5. In our opinion, it is more reasonable the results of ICA method where variable Disc contribute only to dimension 5 because of the interpretation of results are 
Table 2: Variable contributions in the independent component analysis.

\begin{tabular}{lrrrrr}
\hline & Dim.1 & Dim.2 & Dim.3 & Dim.4 & Dim.5 \\
\hline Disc & 0,15 & 0,16 & $-0,08$ & 0,13 & $\mathbf{0 , 9 4}$ \\
CCont & $\mathbf{- 0 , 7 7}$ & $-0,24$ & $-0,12$ & $-0,16$ & $-0,36$ \\
CEdif & $\mathbf{- 0 , 6 5}$ & $-0,22$ & 0,02 & $-0,03$ & $-0,49$ \\
NetDen & $\mathbf{- 0 , 6 5}$ & $-0,21$ & $-0,02$ & $-0,11$ & $-0,05$ \\
FSpace & $\mathbf{0 , 9 0}$ & $-0,06$ & 0,07 & 0,14 & 0,20 \\
Frag & 0,38 & $\mathbf{0 , 6 9}$ & $-0,17$ & 0,19 & $-0,01$ \\
Shape & 0,12 & 0,30 & $-0,03$ & $\mathbf{0 , 9 4}$ & 0,19 \\
Fractal & 0,14 & 0,14 & 0,01 & $\mathbf{0 , 9 1}$ & 0,06 \\
Dist & $-0,07$ & $-0,25$ & $\mathbf{0 , 9 5}$ & $-0,07$ & $-0,11$ \\
sdDist & 0,03 & 0,05 & $\mathbf{1 , 0 0}$ & $-0,10$ & 0,09 \\
cvDist & 0,24 & $\mathbf{0 , 6 9}$ & 0,24 & 0,03 & 0,48 \\
Gini & 0,25 & $\mathbf{0 , 7 7}$ & $-0,11$ & 0,06 & 0,14 \\
\hline
\end{tabular}

clearer. As a conclusion, the results obtained by both methods are similar, coherent and consistent for dimensions 1 to 4 and with differences in the case of dimension 5 .

In final part of Table 3, it can be seen the percentages of variance explained for each factor and cumulative variance explained. Notice that dimensions 1-4 explain most of the variance

Table 3: Variable contributions in the multivariate factor analysis.

\begin{tabular}{lccccc}
\hline & Dim.1 & Dim.2 & Dim.3 & Dim.4 & Dim.5 \\
\hline Disc & 0,49 & $\mathbf{0 , 5 7}$ & $-0,16$ & 0,13 & 0,41 \\
CCont & $\mathbf{- 0 , 7 7}$ & $-0,28$ & $-0,12$ & $-0,19$ & $-0,41$ \\
CEdif & $\mathbf{- 0 , 6 5}$ & $-0,34$ & $-0,02$ & $-0,07$ & $-0,07$ \\
NetDen & $\mathbf{- 0 , 9 5}$ & $-0,18$ & 0,03 & $-0,13$ & 0,22 \\
FSpace & $\mathbf{0 , 7 1}$ & 0,19 & 0,04 & 0,15 & 0,12 \\
Frag & 0,40 & $\mathbf{0 , 5 2}$ & $-0,29$ & 0,22 & 0,07 \\
Shape & 0,16 & 0,24 & $-0,12$ & $\mathbf{0 , 8 8}$ & 0,05 \\
Fractal & 0,16 & 0,06 & $-0,05$ & $\mathbf{0 , 9 8}$ & 0,02 \\
Dist & $-0,03$ & $-0,35$ & $\mathbf{0 , 9 2}$ & $-0,13$ & 0,01 \\
sdDist & 0,10 & 0,22 & $\mathbf{0 , 9 7}$ & $-0,05$ & $-0,02$ \\
cvDist & 0,23 & $\mathbf{0 , 8 7}$ & 0,23 & 0,13 & 0,03 \\
Gini & 0,34 & $\mathbf{0 , 6 8}$ & $-0,19$ & 0,14 & 0,03 \\
\hline \hline & Dim.1 & Dim.2 & Dim.3 & Dim.4 & Dim.5 \\
\hline Eigenvalue & 3,36 & 2,40 & 1,91 & 1,96 & 0,34 \\
Variance \% & 28,0 & 20,0 & 15,9 & 16,3 & 2,8 \\
Cumulative & 28,0 & 44,0 & 64,0 & 80,3 & 83,1 \\
Variance \% & & & & & \\
\hline
\end{tabular}


while dimension 5 only explains a little part of variance. This reason reinforces considering Dim5 as a dimension associated only to variable Disc as show the results of ICA method.

\section{DISCUSSION}

The multivariate analysis has allowed identifying five dimensions or latent variables associated of urban sprawl phenomenon. By observation of variables that are integrated in each dimension is it possible associating it to following characteristics: density, fragmentation, distance, complexity and extension.

The dimension 1, that we name as Density, includes mainly the information provided by variables CCont, CEdif, NetDen and FSpace. All these variables show information about intensity of land uses or density: concentration of population and building, density or percentage of open spaces. The first three variables produce negative effects in urban sprawl (major value of variable minor urban sprawl) while the variable FSpace has a positive effect.

The dimension 2, which we name as Fragmentation, includes the variables Frag, cvDist and Gini. These variables are associated to fragmentation and dispersion of urban polygons. The three variables are a positive correlation with urban sprawl phenomenon.

The dimension 3, which we name Distance, includes as a main variables Dist and $s d$ Dist. Both are implicated with distance between urban zones or urban polygons. Both had a positive correlation with urban sprawl.

The dimension 4, which we name Complexity, includes as a main variables Shape and Fractal. Both are implicated with the form of urban zones or urban polygons and indicate the complexity of urban polygon forms.

The dimension 5, which we name Extension, includes almost exclusively the variable Disc. This variable describes the importance of discontinuous urban zones into each municipality.

Figures 1-5 show the distribution of values of each dimensions for all the municipalities of Valencian Community (VC). The reed zones are the municipalities that have more urban sprawl according to each dimension. In contrast, the green zones show the municipalities with low urban sprawl according to each dimension. Of course, all the municipalities can have a high urban sprawl for one dimension (or kind of urban sprawl) and low for other. Remember that the five dimensions are independent between them.

Each dimension probably has different contribution to explain the urban sprawl phenomenon. For this reason it is important evaluating each contribution and, in consequence, what are the main dimensions that explain the phenomenon. It is possible analyzing effects and its importance, produced for each dimension on urban sprawl level. Gielen et al. [16] made a previous classification of this urban sprawl level for each municipality of VC. Now this paper show a descriptive analysis based in univariate and bivariate graphics that connect the urban sprawl level with the dimensions obtained for each municipality.

Figure 6 shows, for each dimension, the distribution of its values in function of urban sprawl level of municipalities. Each figure shows the distribution of dimension's value in color black and, in dark blue, light blue, yellow, orange and reed colors, the distributions of municipalities with very low, low, medium, high and very high urban sprawl level. Figure shows a clear relationship between dimension 1 and 2 and levels of urban sprawl (more urban sprawl for more dimension value). In contrast, the dimension 3 not shows some relationship with urban sprawl level. In the case of dimension 4, maybe it exist a relationship but is not clear. Finally, dimension 5 could have a relationship with urban sprawl level but it is not lineal. 


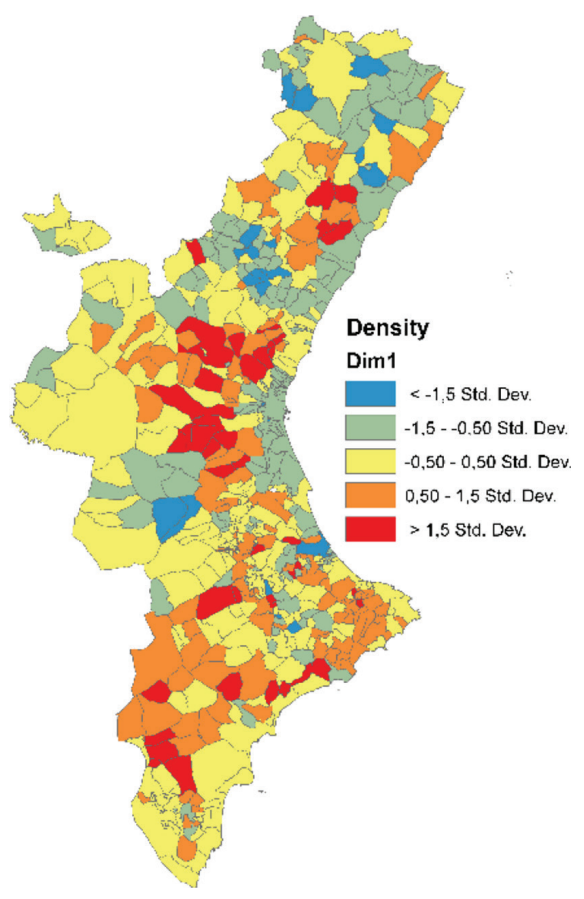

Figure 1: Distribution Dim.1-Density in VC.

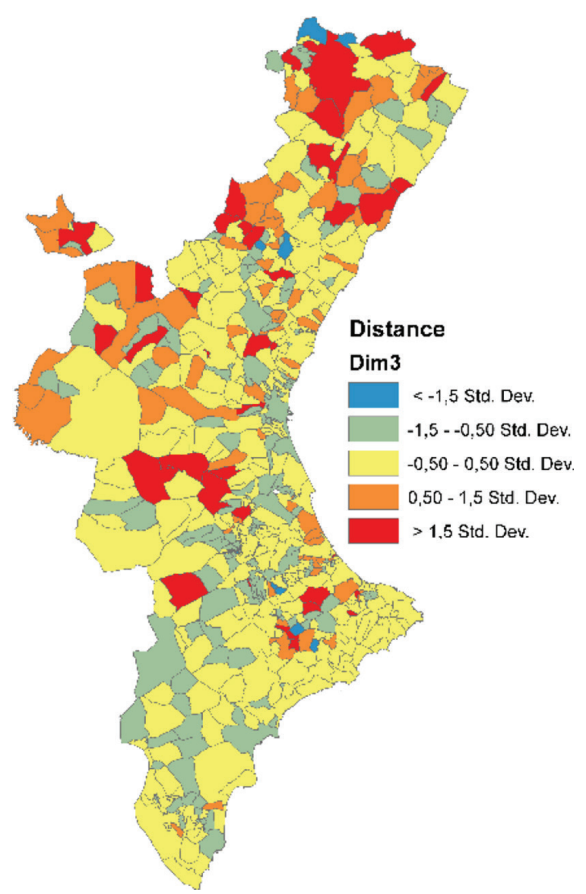

Figure 3: Distribution Dim.3-Distance in VC.

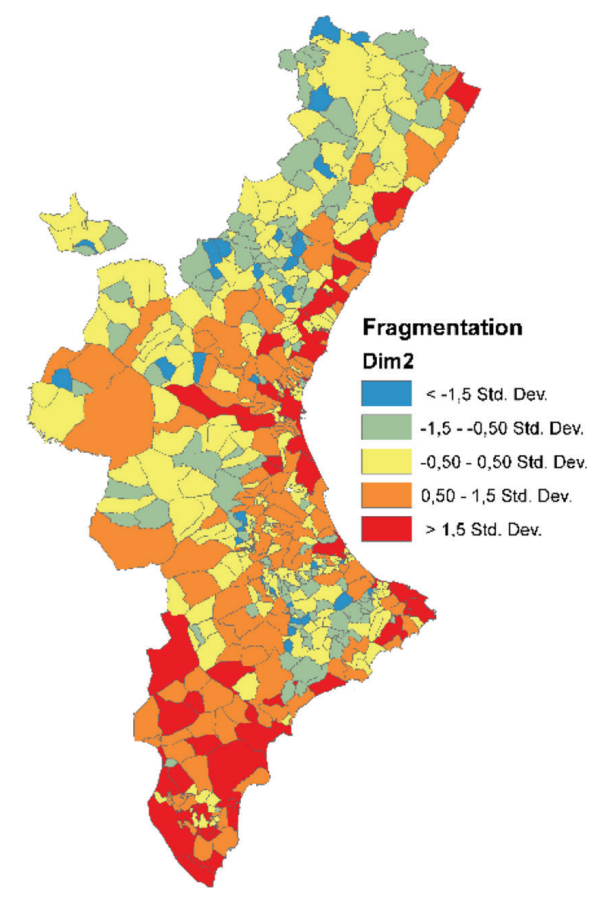

Figure 2: Distribution Dim.2-Fragmentation in $\mathrm{VC}$.

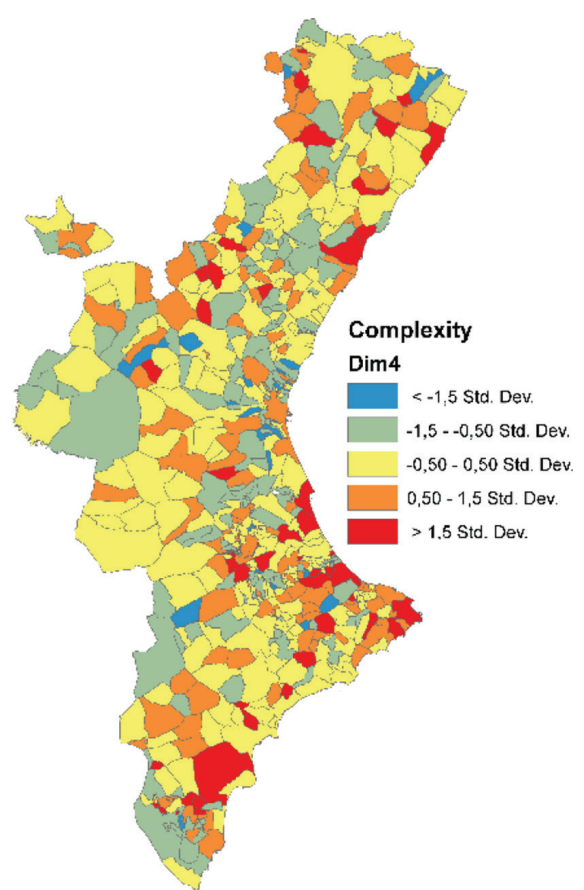

Figure 4: Distribution Dim.4-Complexity in $\mathrm{VC}$ 


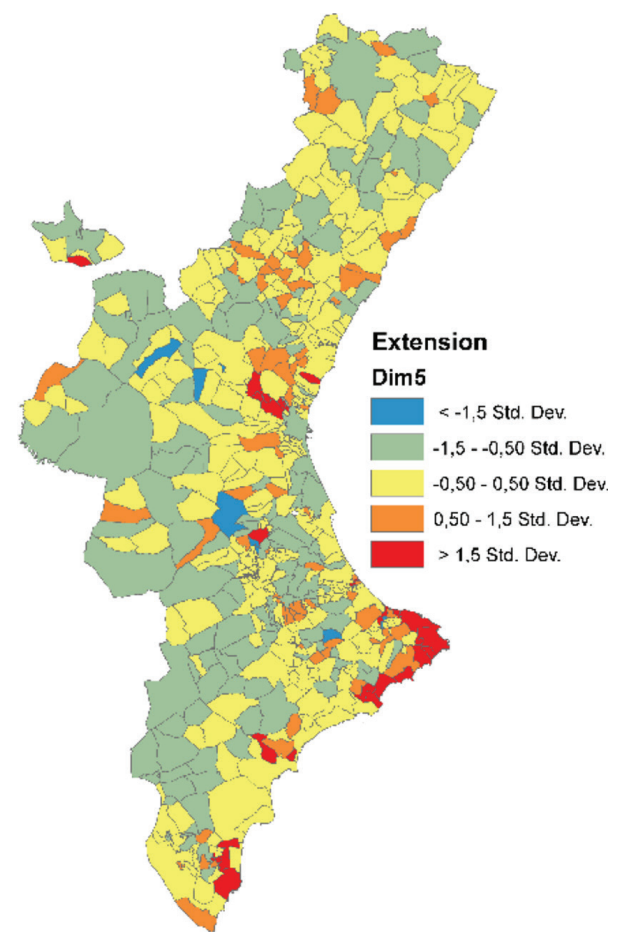

Figure 5: Distribution Dim.5-Extension in VC.

Figure 7 shows bi-dimensional graphics where are drafted dimension by dimension and each point is colored in function of urban sprawl level. These graphics allow seeing the relationship between two dimensions and the urban sprawl level.

The interaction between dimensions 1 and 2 clearly identifies the level or urban sprawl. In fact, reed points (which have high level of urban sprawl) are concentrated in zone high right where dimensions 1 and 2 have the highest values. In contrast, the other pairs of dimensions not show the same relationship.

The interaction between dimensions 1 and 4 should have a little effect on urban sprawl level. In this case, the data in Figure 7 show that municipalities with high urban sprawl present average values in dimension 1 but, in contrast, high values in dimension 4. Similar situation exist in the cases of relationship between dimensions 1 and 5 and dimensions 1 and 3. This analysis confirms the conclusions of Gielen et al. [16].

However, it is important understand these conclusions. The relationship between dimensions 1 and 2 not signifies that the other dimensions are not important. Really, signify that dimensions 3, 4 and 5 explain some kind of urban sprawl without relationship with other dimensions. Therefore, the analysis identifies four kind of urban sprawl: the urban sprawl explained by dimensions 1 and 2 (Density and Fragmentation) and the urban sprawl explained by the other dimensions 3, 4 and 5 (Distance, Complexity and Extension).

Finally, Figure 8 shows a multidimensional map made overlapping the main dimension value for each municipality. Therefore, this map is a map of urban sprawl or a map where is 

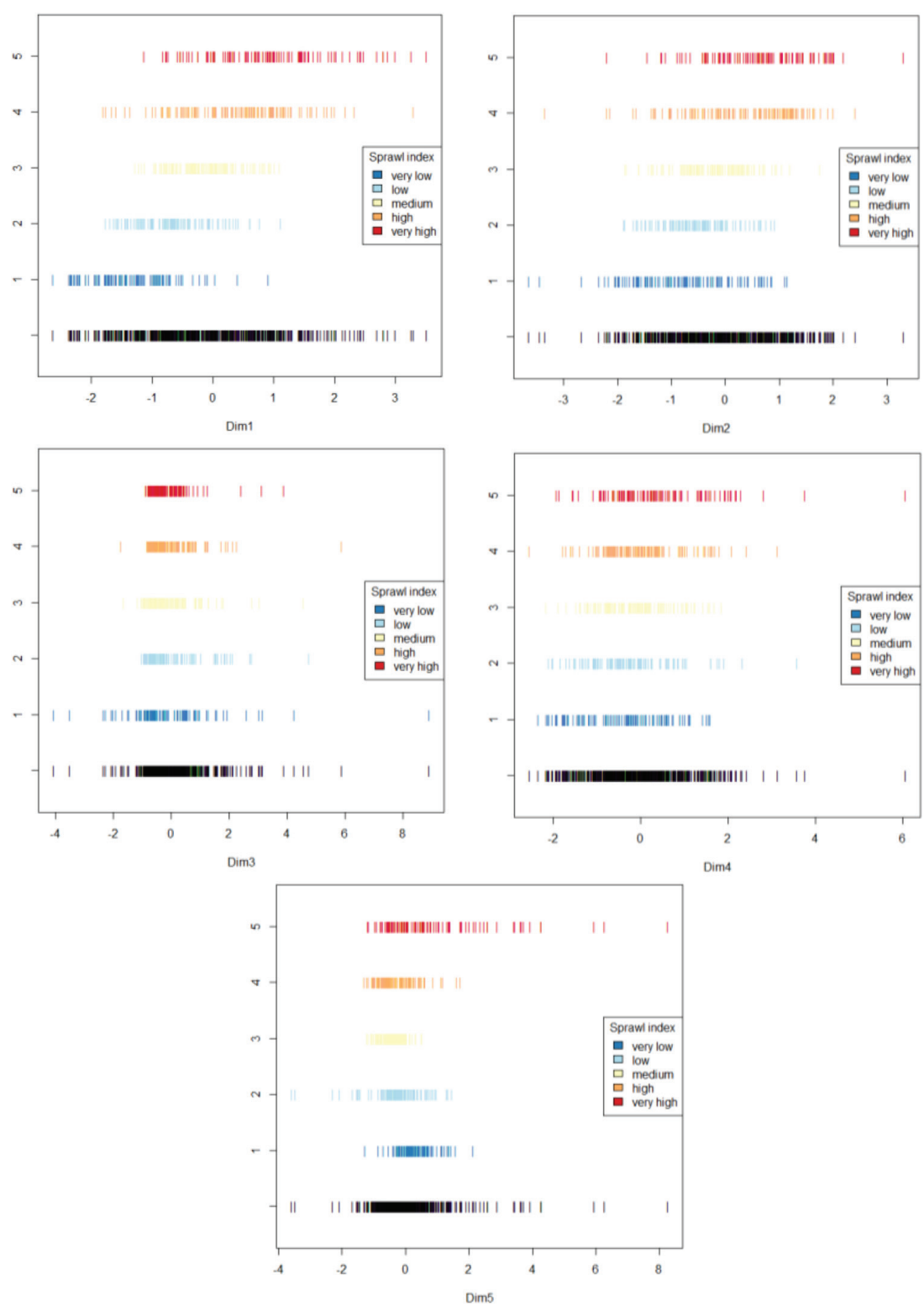

Figure 6: Distribution of each dimension in function of urban sprawl levels. Source: Gielen et al. [16].

drowned what municipalities present urban sprawl and what is the main kinds of urban sprawl for each municipality. This map allows explain the urban sprawl phenomenon by the different dimensions and shows the characteristics of urban model on each municipality.

From the observation of the map obtained to Valencian Region can draw some interesting conclusions. For example, we can see that municipalities with very high level of urban 

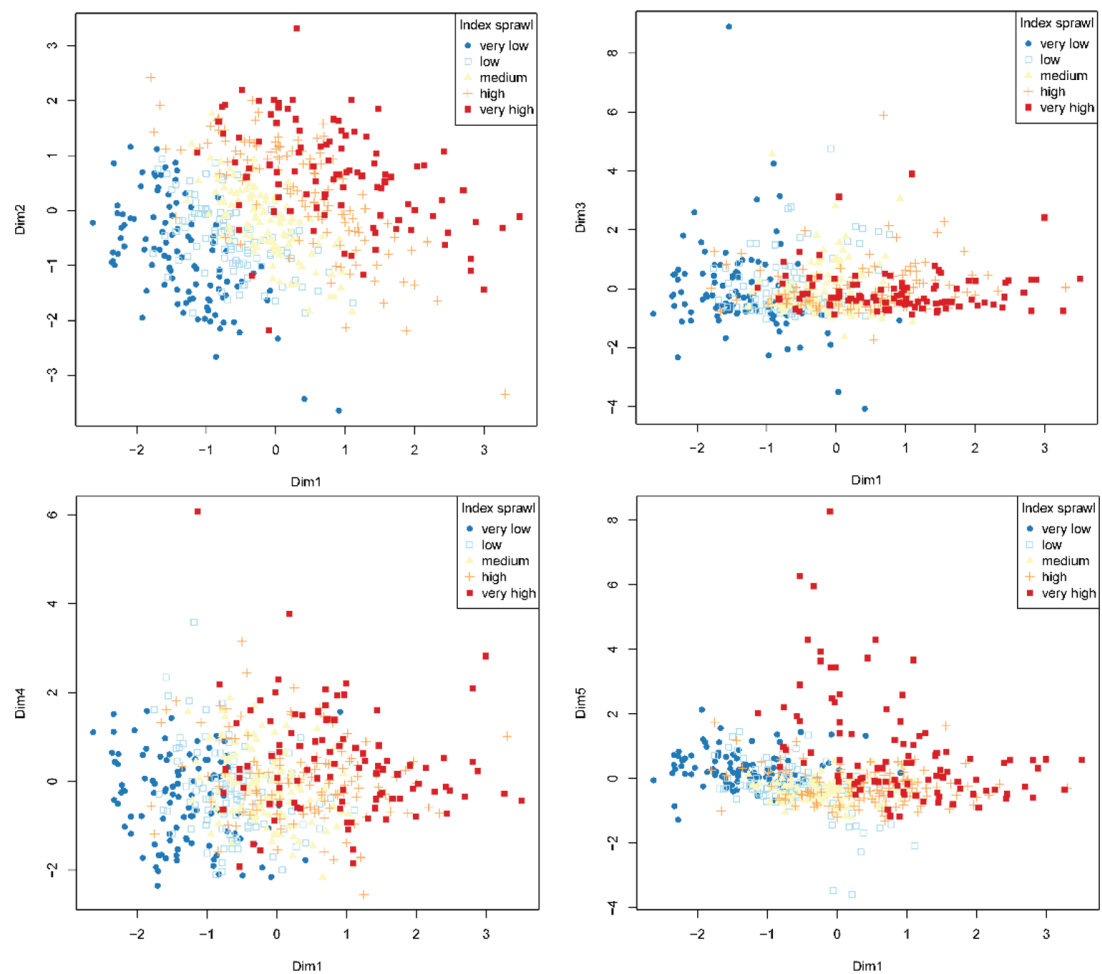

Figure 7: Bi-dimensional histograms with urban sprawl level. Source: Gielen et al. [16].

sprawl have very different values for different dimensions. That is, it not exist an only urban sprawl model but some models into Valencian Community. In general, Dim.1 or Density is present in municipalities with urban sprawl but the variable is not sufficient to explain the situation. That is the case, for example, of many rural municipalities located in the mountains far from the coast. In contrast, this dimension is very important around the Metropolitan Area of Valencia and is the main variable that explain the urban sprawl phenomenon in this area. Now, ever in this area, it exist some little municipalities with big extension of single-family homes where the main variable that explain the urban sprawl is Dim.5-Extension.

A second big area with high level of urban sprawl is located in coastal zone of La Nao Cape, halfway between Valencia and Alacant cities. In this case, the model of urban sprawl is characterized by high values of dimension 5 and also dimensions 2 and 4 . This zone is a touristic 'sun and beach' model. Almost all municipalities are totally occupied by singlefamily homes with low density (Dim.5-Extension). But the orography produces fragmentation (Dim.2) and complexity of urban forms (Dim.4).

The third big area with high level of urban sprawl is located on the south of Alacant. In this case, the main dimension that explain the urban sprawl model is the high fragmentation in urban areas with low density (Dim.2). Is similar to the 'sun and beach' touristic model but with more extension and orography more plain. 


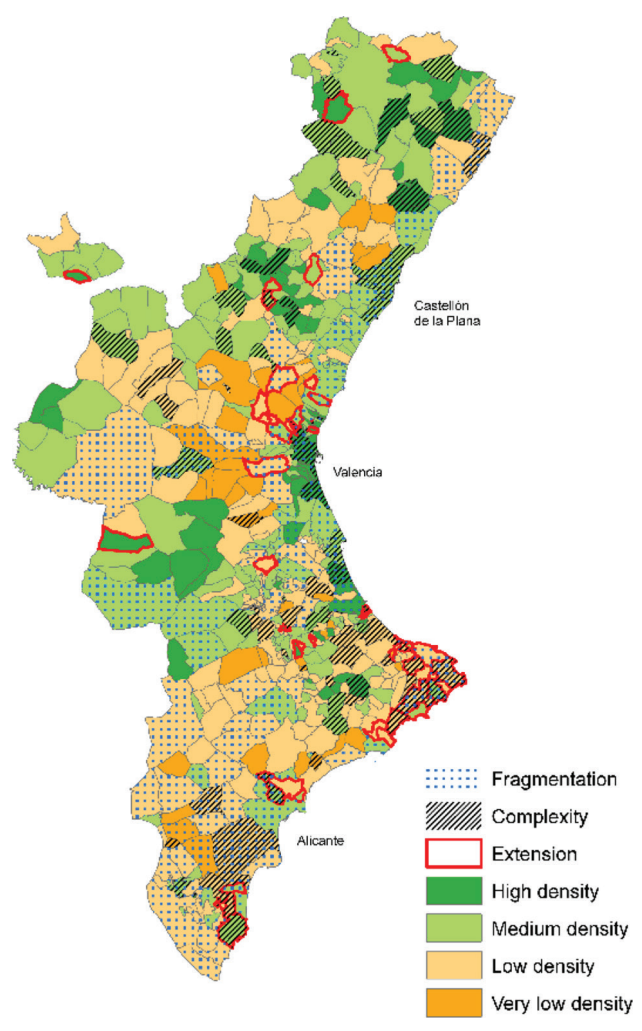

Figure 8: Multidimensional map of urban sprawl in VC.

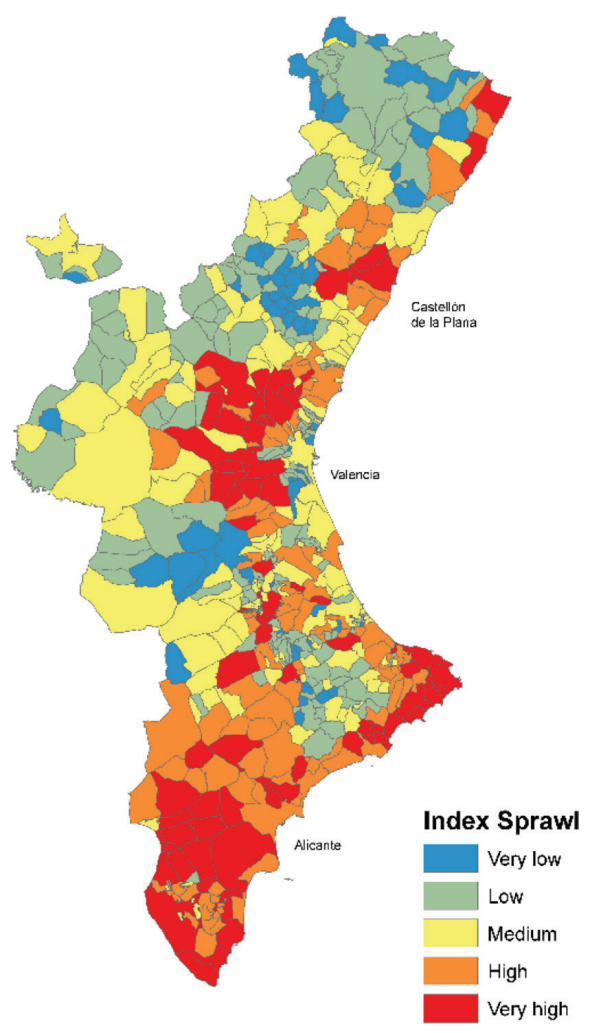

Figure 9: Map of urban sprawl level. Source: Gielen et al. [16].

\section{CONCLUSIONS}

The urban sprawl phenomenon is complex. Statistical multivariate techniques have allowed identifying five dimensions between a set of 12 variables that are latent variables about urban sprawl. Authors name these five variables as Density, Fragmentation, Distance, Complexity and Extension. This fact confirms that urban sprawl is a complex phenomenon.

The analysis of five latent variables applied on the Valencian Community at municipal level allows identifying different urban sprawl processes especially in Metropolitan Area of Valencia and different Mediterranean coastal areas. The analysis shows that urban sprawl phenomenon present different models as a results of combination of different dimensions. In fact, Valencian Community present different urban sprawl models with different combinations of one or more dimensions.

In addition, the results show the urban sprawl phenomenon as a multidimensional process. This fact allows define the urban sprawl as an urban model of occupation of the territory, characterized by low-density settlements spread over large areas, fragmented in several urban units, distant between them that define a complex structure.

\section{REFERENCES}

[1] Moreira, J.M., Urbanismo expansivo de la utopía a la realidad. Reflexiones desde la información ambiental. In Gozálvez, V. \& Marco, J.A. (eds.), Geografía: retos ambientales y territoriales, Universidad de Alicante: Alicante, pp. 125-164, 2012. 
[2] Nechyba, T. \& Walsh, R., Urban sprawl. Journal of Economic Perspectives, 18(4), pp. 177-200, 2004.

https://doi.org/10.1257/0895330042632681

[3] Pichler-Milanovic, N., European urban sprawl: sustainability, cultures of (Anti)Urbanism and "Hybrid Cityscapes". Dela, 27, pp. 101-133, 2007.

https://doi.org/10.4312/dela.27.6.101-133

[4] Patacchini, E. \& Zenou, Y., Urban sprawl in Europe. Papers on Urban Affairs, 2009(1), pp. 125-149, 2009.

[5] EEA, Urban sprawl in Europe. The ignored challenge. Report No 10/2006, 2006.

[6] EEA, Urban sprawl in Europe. Joint EEA-FOEN report. Report No 11/2016, 2016.

[7] Susino, J. \& Duque Calvache, R., Veinte años de suburbanización en España (19812001). El perfil de sus protagonistas. Documents d'Anàlisi Geogràfica, 59(2), pp. 265-290, 2013. https://doi.org/10.5565/rev/dag.31

[8] Miralles i Garcia, J.L., El darrer cicle immobiliari al País Valencià. O el progrés de la miseria, Fundació Nexe: València, 2014.

[9] Miralles i Garcia, J.L., Urban coastal development in Valencian country: a paradigmatic case of non-sustainable development. International Journal of Sustainable Development and Planning, 10(3), pp. 301-314, 2015. https://doi.org/10.2495/sdp-v10-n3-301-314

[10] Gielen, E., Costes del urban sprawl para la administración local. El caso valenciano [Doctoral thesis], Universitat Politècnica de València, 2016.

https://doi.org/ 10.4995/Thesis/10251/62866

[11] Cantarino, I., Torrijo, F.J., Palencia, S. \& Gielen, E., Assessing residential building values in Spain for risk analyses - application to the landslide hazard in the Autonomous Community of Valencia. Natural Hazards and Earth System Sciences Journal, 14, pp. 3015-3030, 2014. https://doi.org/10.5194/nhess-14-3015-2014

[12] Colaninno, N., Cerda, J.F. \& Roca, J., Spatial patterns of land use: morphology and demography, in a dynamic evaluation of urban sprawl phenomena along the Spanish mediterranean coast. 51st European Congress of the Regional Science Association International, pp. 1-18, 2011.

[13] Shlens, J., A tutorial on principal component analysis. Available at: https://www.cs.cmu. edu/ elaw/papers/pca.pdf. (Accessed 5 May 2017).

[14] Hyvärinen, A. \& Oja, E., Independent component analysis: algorithms and applications. Neural Networks, 13(4-5), pp. 411-430, 2000.

https://doi.org/10.1016/s0893-6080(00)00026-5

[15] Graffelman, J., Factor analysis. In Encyclopedia of Environmetrics. Wiley, 2013.

[16] Gielen, E., Riutort-Mayol, G., Palencia Jiménez, J.S. \& Cantarino-Martí, I., An urban sprawl index based on multivariate and Bayesian factor analysis with application at the municipality level in Valencia. Environment And Planning B-Planning \& Design, pp. 1-27, 2017.

https://doi.org/10.1177/2399808317690148 